\title{
The Design and Application of an Automatic Course Generation System for Large-Scale Education
}

\author{
Xiaohong Tan \\ E-learning Lab \\ Shanghai JiaoTong University \\ Shanghai, China \\ e-mail: xhtan@sjtu.edu.cn \\ Yan Wang \\ Department of Computer Science \\ Shanghai JiaoTong University \\ Shanghai, China \\ e-mail: wangyan8383@sjtu.edu.cn
}

\author{
Carsten Ullrich \\ Department of Computer Science \\ Shanghai JiaoTong University \\ Shanghai, China \\ ullrich_c@sjtu.edu.cn \\ Ruimin Shen \\ Department of Computer Science \\ Shanghai JiaoTong University \\ Shanghai, China \\ rmshen@sjtu.edu.cn
}

Abstract - In China, the number of online learners who attend formal education has quadrupled in the last 5 years to 8.2 millions until the end of 2008. How can online teachers build and update web-courses for such a large numbers of online students - courses that ideally respect the different requirements of the students? In this paper we describe an automatic course generation System (ACGS) developed at the Shanghai Jiao Tong University (SJTU). In this ACGS, teachers can build web-based courses according to their own instructional plan and publish the web-based courses without requiring technological support. Teachers can also update the web-courses whenever the instructional objective changes. The web-course learning environment generated from this system takes into account pedagogical scenarios. The ease of use of our system is illustrated by its quickly increasing number of users. About 50 teachers in the SJTU School of Continuing Education (SOCE-SJTU) have developed 45 web-courses in only two months. These 45 web-courses have been provided to about 5800 online learners in the last 2009 autumn semester alone.

Keywords-Course generation; large scale education; pedagogical scenario

\section{INTRODUCTION TO CHINESE ONLINE HIGHER EDUCATION}

The Chinese Ministry of Education started distance education in 1998. Today, 66 universities are authorized to engage in online degree education. These online students mainly consist of adults and part-time learners. During the last 12 years, a total of 8.2 million students enrolled in an online university, with 3.5 million students studying online in 2009 alone. According to the published statistic number on the website of the Chinese Ministry of Education [1], the number of online students has quadrupled in the last 5 years. The topics taught in Chinese online education cover 11 different disciplines and 299 specialties. More than 20.000 courses have been authored by the Chinese online educational institutions.
In order to improve the quality of web courses and their authoring development, the Chinese Ministry of Education began to curate high quality courses, the so-called National Level Excellent Web-Courses (NLEC). Today, 149 of such courses were authored from total 65 universities. While authoring or adapting a NLEC course is resource intensive. It requires teams that include course teachers, instructional designers, and technicians. The developing cycle is long, expensive, and subsequent updates of content require help by technicians. As a consequence, most teachers still teach the traditional way by using their own resources, using Word documents and PowerPoint slides.

The contribution of our work is the following. We present an automatic course generation system that generates courses according to the individual teacher's plan. The system is applied in large scale online learning, namely at the SJTU School of Continuing Education (SOCE-SJTU), an online college with 26000 students.

\section{RELATED WORK}

The existing work on courseware generation is abundant. Early research on the Dynamic Courseware Generator (DCG) by Vassileva ([3]) set the foundations most of today's course generation (CG) is still based on. ELM-ART [7] used a concept-based indexing of the educational materials which allows building a secondary navigation map. The WINDS project [8] focused on the authoring process of adaptive material hypermedia.

Later approaches in CG (such as [4], [5], [9], [10]) all have in common that the pedagogical knowledge used in these systems is rather rudimentary [2]. As a consequence, these systems cannot generate with respect to different learning goals. In contrast, Paigos [2] is a CG system that uses a significant amount of pedagogical knowledge implemented as a Hierarchical Task Network Planner (HTN) and handles different learning goals (called scenarios). However, Paigos focuses on domains that are highly structured, such as mathematics or physics, and its 
usage, although involving several European universities does not qualify as large-scale.

A parallel line of research is investigating how to provide adaptability in large scale web course development based on educational specifications and standard, such as IMS, SCORM ([6], [11], [12]). However, this work does not address how to construct user-centered scenarios in LMS and do not support pedagogical scenarios.

To summarize, the disadvantages of most existing automatic course generation system are (1) they only generate a single, limited type of course; (2) implement only a restricted amount of pedagogical knowledge; (3) they have not been evaluated in large scale education environment; (4) they mainly focus on the needs of the students, which differ from the needs of teachers.

\section{THE GENERAL FRAMEWORK OF THE AUTOMATIC COURSE GENERATION SYSTEM}

The main aim of the ACGS at this point is to support teachers by generating courses that implement their goals regarding the outcome and coverage of the taught content. In brief, the teacher decides about the content of a course and designs a schedule, which gets filled by reusing learning objects stored in a resource repository. The detailed process flow is illustrated in figure 1. It starts with the teacher determining the overall objectives of a course and the current knowledge state of the students. This results in a broad course outline, which is then refined into a detailed instructional plan, taking into account the degree targeted by the students. These documents follow a given syntax, and are written as an Excel file and uploaded to the system.

An instructional plan is represented by a table with the fields "Unit name, learning goal, learning hint, important concepts, difficulties, recommended learning time". Table 1 contains an example of an instructional plan.

The teacher schedule is arranged week by week. A teaching schedule is represented by a table with the fields "No of week, recommended learning time, learning unit, main concepts and main learning activity".

Following [9], we consider an instructional plan as connecting two different spaces. The first one is the knowledge space, which includes the concepts and the relationship among them - actually a network of concepts, stored in the Knowledge repository (KR). The second is the resource space, stored in the Resource Repository. The learning objects in the RR link to the concepts in KR via their metadata. Based on the uploaded documents, the knowledge extracting process generates the hierarchy of the concepts used in the course using the overall concept structure defined in the Knowledge Repository. The knowledge extracting process uses the implemented instructional plan produced by the teacher and retrieves those concepts used in the plan, called CKR (Course Knowledge Domain).
Based on the CKR and the resources available in the $R R$, the course generator selects the specific resources of the course, according to the scenario chosen by the teacher. ACGS offers more than 10 scenarios, for instance experimentation learning scenario for computer science courses, case studies for business courses, and task-based foreign language learning.

\section{APPLiCATION OF ACGM}

The first version of the system was completed in August 2009 and used by two computer science teachers at SOCE-SJTU for their course on Data Structures. The two lecturers developed two courses for different target audiences (one for a 13 weeks class, one for a 16 weeks class). The teachers authored the courses within three weeks, without requiring help by instructional designer or technical experts. The courses are accessible online at http://jpkc.onlinesjtu.com/CourseShare/Courses/Theme1/De fault.aspx? courseid $=701018$ and http://jpkc.onlinesjtu.com/CourseShare/Courses/Theme1/De fault.aspx? courseid $=601018$.

The courses were used in a class with 320 online learners and another one with 78 students.

After these initial test runs, the platform was used by 50 lecturers in SOCE-SJTU. 45 Web-based courses have been generated from ACGS in two months. About 5800 online students used these courses in the autumn semester 2009.

\section{CONCLUSION AND FUTURE WORK}

The ACGS system we presented in this paper offers a pragmatic, easy-to-use way of enabling instructors to automatically create courses that are adapted to the common needs of their learners. The system aims at supporting learning and teaching in settings where the foremost goal is to enable access to education to large numbers of citizens as quickly as possible. These settings come with their own set of problems and challenges, and are not restricted to China, but also apply to other countries that are still developing their educational sector. ACGS offers adaptation to the goals of groups of learners, namely those learners who attend a specific class. Teachers become able to quickly generate courses for their classes, by reusing learning objects stored in a repository. These courses are adapted according to scenarios selected by the teachers. The scenarios implement pedagogical knowledge. This way, even teachers with limited pedagogical knowledge are enabled to build such adapted courses.

Future work will consist of a thorough evaluation of ACGS. We will collect opinions and feedback by teacher as well as learners to evaluated the perceived usefulness and adequacy of the system. We will also investigate how ACGS's functionality can be made best available to the learners themselves. In the current implementation, it is hard to do, as the system generates HTML pages for every course. Storing and making accessible these pages for more than 20.000 students is a challenging task. 


\section{REFERENCES}

[1] The statistic data on the website of Ministry of the People's Republic of China, Accessed online at http://www.moe.edu.cn/edoas/website18/level2.jsp?tablename $=1020$

[2] C. Ullrich, "Pedagogically Founded Courseware Generation for WebBased Learning -- An HTN-Planning-Based Approach Implemented in PAIGOS", September, 2008. Vol. 5260 Springer-Verlag.

[3] J. Vassileva, R. Deters, Dynamic courseware generation on the www. British Journal of Educational Technology. 29(1), 5-14,1998

[4] AI. Cristea, A De Mooij, Adaptive Course Authoring: My Online Teacher. Predeeding of ICT,2003, Papeete, French Polynesia.

[5] Méndez, N. D. D., Ramírez, C. J., \& Luna, J. A. G,. IA planning for automatic generation of customized virtual courses. In Frontiers of Artificial Intelligence And Applications, Proceedings of ECAI 2004, volume 117 (pp. 138-147). Valencia (Spain): IOS Press.

[6] J. G. Boticario, O. C. Santos, An open IMS-based user modelling approach for developing adaptive learning management systems. Journal of Interactive Media in Education, 2007
[7] P. Brusilovsky, E. Schwarz, \& G. Weber, ELM-ART: An intelligent tutoring system on World Wide Web. Lecture Notes in Computer Science, 1996 - Springer. 261-169

[8] M. Specht, M. Kravcik, L. Pesin, \& R. Klemke, Authoring Adaptive Educational Hypermedia in WINDS. Proceedings of ABIS2001 In: Online-Proc.

[9] P. Karampiperis \& D. Sampson 2004, Adaptive Instructional Planning using Ontologies. Proceedings of the IEEE international of conference on Advanced Learning Technologies (ICALT'04).

[10] Y. Huang, J. Chen, T. Huang, Y. Jeng, Y. Kuo,. Standardized course generation process using Dynamic Fuzzy Petri Nets. Expert systems with applications. 34(2008) 72-86

[11] M. Baldoni, ,C. Baroglio, V. Patti,\& L. Torraso, Reasoning about learning object metadata for adapting SCORM courseware. L. Aroyo and C. Tasso, (Eds) Engineering the Adaptive Web., CS-Report 0418, Technische Universiteit Eindhoven, pp. 4-13, 2004

[12] J. G. Boticario, O. C. Santos . Issues in developing adaptive learning management systems for higher education institutions. International Workshop on Adaptive Learning and Learning Design, Adaptive Hypermedia. Accessed online on 1 March 2007 at: http://www.ia.uned.es/ jgb/publica/ADALE-ocsjgbah06-final.pdf

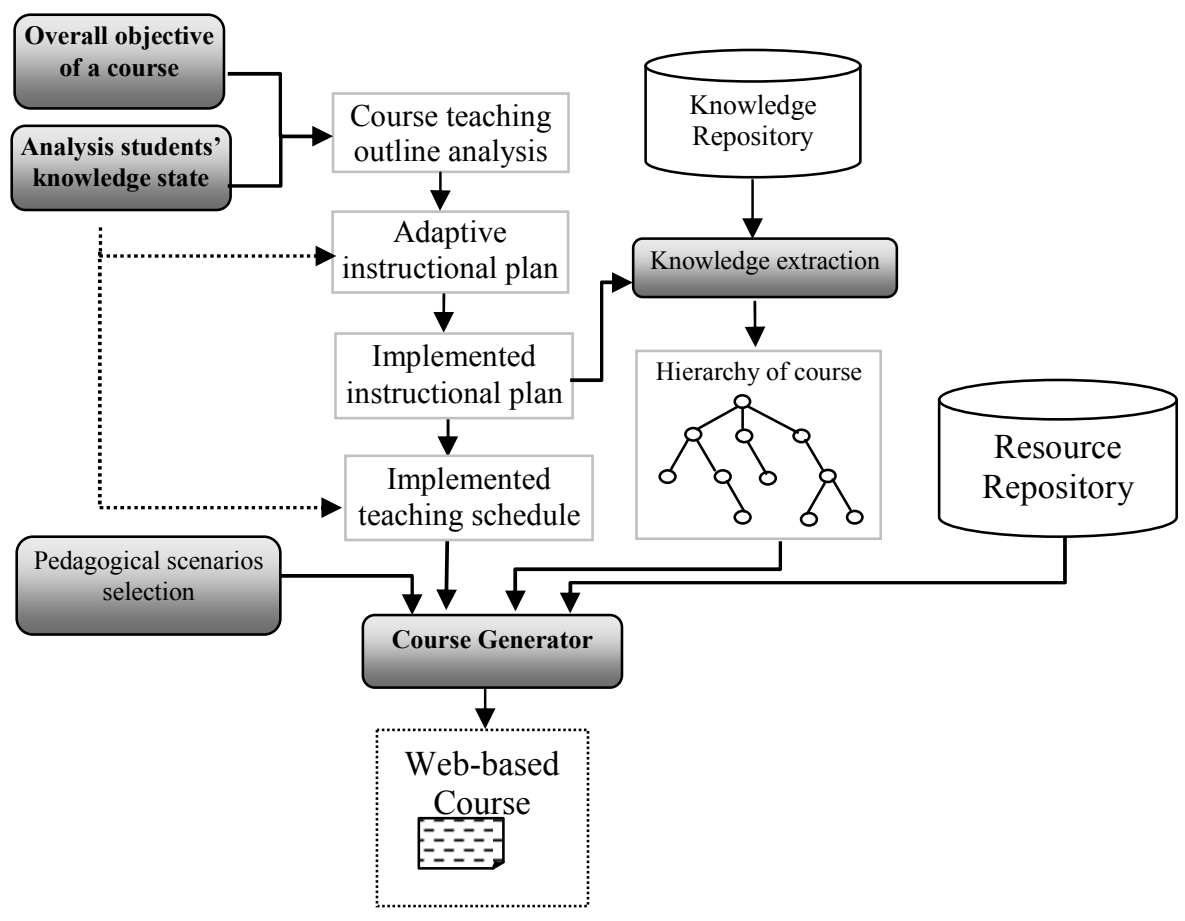

Figure 1. Figure 1: ACGS process flow

Table 1 an example of an instructional plan

\begin{tabular}{|c|c|c|c|c|c|}
\hline $\begin{array}{l}\text { unit } \\
\text { name }\end{array}$ & learning goal & learning strategy & emphasized concepts & difficult concepts & $\begin{array}{l}\text { learning period } \\
\text { recommendation }\end{array}$ \\
\hline $\begin{array}{l}\text { Linear } \\
\text { List } \\
\text { (LL) }\end{array}$ & $\begin{array}{l}\text { 1.Master the relation among } \\
\text { the elements in LL; } \\
\text { 2.Becoming familiar with } \\
\text { two storing structures of LL: } \\
\text { Sequence storing LL (SLL) } \\
\text { and Chain storing LL (CLL); } \\
\text { 3.Understanding the basic } \\
\text { operation LL }\end{array}$ & $\begin{array}{l}\text { LL is the basic and } \\
\text { simplest structure. It is also } \\
\text { the foundation and } \\
\text { emphasis of this course. } \\
\text { Pay attention to the } \\
\text { storing formats of LL, and } \\
\text { the basic algorithms. }\end{array}$ & $\begin{array}{l}\text { 1.the relation between data } \\
\text { elements; } \\
\text { 2.the format of SLL; } \\
\text { 3.Main algorithms like } \\
\text { insert, delete, etc. } \\
\text { 4.the format of CLL; } \\
\text { 5.Main algorithms for CLL; }\end{array}$ & $\begin{array}{l}\text { 1. Comprehension } \\
\text { of relation of data } \\
\text { elements in LL; } \\
\text { 2.construct } \\
\text { algorithms of CLL, } \\
\text { and the algorithms } \\
\text { of other operation. }\end{array}$ & $\begin{array}{l}\text { 1.Spending two } \\
\text { weeks for this unit; } \\
\text { 2.attendance lectures } \\
\text { for } 8 \text { periods; } \\
\text { 3.experiment to } \\
\text { implement the } \\
\text { algorithms. }\end{array}$ \\
\hline
\end{tabular}

